\title{
The letter of submission: avoiding the promotional genre.
}

Philip Shaw, Aarhus School of Business, Denmark

Akiko Okamura, University of Newcastle, United Kingdom

There is a lot at stake when one submits an article for publication in a journal. The writer of the article risks losing face by having the article rejected, but job security may also hang on publication. The writer is a relatively powerless supplicant, the editor who receives the article is in a powerful position, making a judgement from which there is no appeal.

The article is accompanied it by a letter of submission and the stressful situation is one that might be expected to call for what Bhatia [1] describes as a promotional letter. These are letters written by people who hope to get from the recipient some benefit which he or she is under no obligation to grant. Bhatia's examples are unsolicited sales letters in business [2], and letters of application. One might also think of a graduate student writing to an authority to request use of facilities. Just as a salesperson hopes for a sale or an applicant hopes for a job, article authors are hoping for someone in a stronger position (the editor) to do something that will benefit them (publish the article).

Bhatia characterises promotional letters as having seven moves:

Establishing credentials: we at XY are experts in $A B \ldots . . . .$. I have a degree in....

Introducing the offer (including detailing its contents and indicating its value): we are pleased to announce...I would like to apply for....

Offering incentives: (only in sales letters) a discount is available for.... 
Enclosing documents: For your convenience I enclose a reservation form...I enclose a curriculum vitae

Soliciting response: Please call on me....... look forward to hearing from you

Using pressure tactics: ...only valid up to 31st May Bhatia finds this rare in letters of application but notes I have to give notice here by....

Ending politely: final Thank you for your attention .....I hope you will find my qualifications of use to you

However actual letters of submission are rather short and cool and do not conform to Bhatia's model. The canonical form [3] of such a letter is:

Dear Sir,
Please find enclosed three copies of my paper '...... I s should be
grateful if you would consider it for publication in your journal__
Yours sincerely,

The failure of submission letters to match the general 'promotional' form that seems to be applicable to the power relations involved raises several questions. Is Bhatia's hypothesis that power-relations and the communicative purpose determine the content of the letter simply wrong? Or is its operation suspended here by some subcultural convention? And if so, why? 
We carried out an investigation designed to resolve some of these questions and collected submision letters of four sorts: genuine letters to journals in science/engineering, predominantly civil engineering, written by 26 native speakers of English, similar genuine letters by 23 non-native speakers, attempts by 21 British humanities undergraduates, and attempts by 23 continental-European teachers of English as a foreign language. We also had an intermediate group of 13 'classroom' letters by Finnish early-stage researchers who had submitted little or nothing for publication

We analysed the letters in terms of the language they used [4] and the moves they contained. The genuine letters by science/technology researchers, native and non-natives alike conformed very closely to the canonical form. In particular, all began with the main point - I enclose_for submission -- and only one included any personal information. A few of the non-natives were a little more effusive and thanked the editor for his/her attention.

The letters by British students and continental-European teachers were quite different. They were longer, frequently began with introductory material, and included a variety of promotional moves. The letters from Finnish researchers, for whom the situation was much more real, were very similar.

In terms of Bhatia's model, the non-specialists included moves like the following:

Establishing credentials: details of the history of the paper: The said article is the result of a project I undertook in my country on the topic.'

personal details 'I am working as a researcher in the Dept. of_.. '

Introducing the offer summary of the article contents (very frequent): 'the follow-up study I am reporting in the manuscript enclosed presents two new aspects to the discussion_.' boosting the article's value (mainly non-natives): 'I believe my article gives much insight_. 
Offering incentives: absent

Enclosing documents: By the nature of a letter of submission, this was present in all letters.

Soliciting response: Less than a quarter of the genuine letters included 'I look forward to hearing from you', but nearly half of the non-researchers used the move, in six cases with markers of urgency: 'I hope you will accept my article for publication and get in touch with me at your earliest convenience.' ‘

Using pressure tactics: Relative to the canonical form the letters by non-specialists are more demanding. Instead of the "negatively polite formulation I would be grateful if the enclosed article could be considered for publication in _they tend to say: I enclose an article for publication in_.' They more frequently use hope (I hope you can publish it) and other forms of imposition on the editor (I am sure you are interested to publish this article).

Ending politely: a few letters ended 'I am looking forward to hearing from you and I thank you for your attention'. (As noted above, some specialists from non-English backgrounds did the same, perhaps also influenced by promotional genres.) However most ended with the 'soliciting response' move.

The canonical form offers only negative politeness, leaving the editor free to decide, and making no attempt to establish a personal relationship of even the most rudimentary kind (though this may of course be subverted by other features like the salutation Dear Mick!).

Outsiders, however, do attempt to make the content of the letter match perceived power relations in the way that Bhatia would predict. Non-specialists who are native speakers of English only come a little nearer than non-natives, so the problem is not primarily ignorance of English-language conventions. Correspondingly, non-native specialists only diverge a little from the canonical form, so one may assume that it is indeed a subcultural convention that excludes promotional elements. 
The reason for the conventional coolness of the submission letter has to be sought in features which are shared by US culture and the disciplinary culture of science and technology. American culture is strongly universalist [5], imbued with a belief in the equal application of universal principles rather than consideration of the personal aspects of particular cases. It is also described as 'specific' [5] seeing professional and personal issues as clearly separate, unlike more 'diffuse' cultures which recognise the interdependence of personal and professional relations. Both these characteristics seem also to apply to science and technology, in which truth ostensibly emerges from an impersonal process. In the letter of submission they result in the absence of moves introducing the writer, giving background, recommending the paper, etc. The paper is to be judged against a standard without reference to irrelevant personal details. Furthermore the personal comments which 'maintain good relations' in East Asian letters are 'unbusinesslike' in their American equivalents ([6,7]) and presumably 'irrelevant' in scientific discussion.

In a different terminology [8] American technological culture is described as Utilitarian, with a discourse system based on egalitarian symmetrical relationships. Writers have to pretend they are the equals of the editor, neither superior nor inferior, in the same discourse community, and conceal the actual power relations. Thanking or expressing hope may be against the principle of free and rational choice. An American reviewer of this note confirmed this by commenting that 'expecting or demanding publication is presumptuous and may well precipitate a negative decision on the ms.; on the other hand, begging for publication is obsequious and may well have the same effect.'

While the restrained canonical form may well originate in English-speaking cultural conventions, there is little evidence in our sample that native speakers of English can handle its rhetoric any better than nonnatives, until they have become members of the science/technology discourse community. Even this 
apparently simple genre is deeply embedded in the culture of the discipline, and disciplinary culture in turn is embedded in complex ways in the culture of the dominant nation.

\section{References}

[1] V. K. Bhatia, Analysing Genre. London: Longman, 1993.

[2] M. Pilegaard, "Politeness in written business discourse: a textlinguistic perspective on requests.," Journal of Pragmatics, vol. 28, pp. 223-244, 1997.

[3] J. Swales, "Occluded genres in the academy: the case of the submission letter.," in Academic Writing, E. Ventola and A. Mauranen, Eds. Amsterdam: John Benjamins, 1996.

[4] A. Okamura and P. Shaw, "Culture and Subculture in Transactional Letter Writing," English for Specific Purposes, 1998.

[5] F. Trompenaars and C. Hamden-Turner, Riding the Waves of Culture. London: Nicholas Brealey, 1997.

[6] S. Jenkins and J. Hinds, "Business Letter Writing: English, French, and Japanese," TESOL Quarterly, vol. 21, pp. 327-345, 1987.

[7] J. Ulijn, "The Anglo-Germanic and Latin concepts of politeness and time in cross-atlantic business communication: from cultural misunderstanding to management success," Hermes, Journal of Linguistics, pp. 53-79, 1995.

[8] R. Scollon and S. Scollon, Intercultural communication. Oxford: Blackwell, 1995. 